\title{
Building the E-Commerce Supply Chain of the Future: What Influences Consumer Acceptance of Alternative Places of Delivery on the Last-Mile
}

\author{
Björn Asdecker (D)
}

check for updates

Citation: Asdecker, B. Building the E-Commerce Supply Chain of the Future: What Influences Consumer Acceptance of Alternative Places of Delivery on the Last-Mile. Logistics 2021, 5, 90. https://doi.org/ $10.3390 /$ logistics 5040090

Academic Editor: Robert Handfield

Received: 11 November 2021 Accepted: 8 December 2021 Published: 17 December 2021

Publisher's Note: MDPI stays neutral with regard to jurisdictional claims in published maps and institutional affiliations.

Copyright: (C) 2021 by the author. Licensee MDPI, Basel, Switzerland. This article is an open access article distributed under the terms and conditions of the Creative Commons Attribution (CC BY) license (https:/ / creativecommons.org/licenses/by/ $4.0 /)$.
Department of Business Administration, University of Bamberg, 96045 Bamberg, Germany; bjoern.asdecker@uni-bamberg.de; Tel.: +49-951-8632521

\begin{abstract}
Background: To cope with the expected further growth in e-commerce and to be able to continue delivering at low costs, new concepts for the last-mile are needed. This paper reviews the literature and qualitatively investigates which factors influence the acceptance of four alternative place-of-delivery innovations in a business-to-consumer (B2C) context: (1) parcel lockers, (2) reception boxes, (3) trunk delivery, and (4) home access systems; Methods: The available literature was reviewed. Furthermore, 37 interviews were conducted and analyzed using the deductive category development method. In the following, abductive reasoning can derive detailed research models that may form the basis for future confirmative studies; Results: The research gains more detailed insights into how consumers perceive innovative last-mile place-of-delivery concepts. The study provides a clearer picture of what factors influence the intention to use such alternative services; Conclusions: The results can be used by logistics service providers and e-tailers through targeted communication efforts and lay the groundwork for further confirmatory research.
\end{abstract}

Keywords: last-mile; place of delivery; e-commerce; customer acceptance; parcel lockers; reception boxes; trunk delivery; home-access systems

\section{Introduction}

Within the e-commerce supply chain, the so-called "last-mile" towards the customer is arguably one of the biggest challenges. On the one hand, logistics networks face capacity issues due to the enormous growth rates in recent years [1]. The COVID-19 pandemic further accelerated this trend in favor of e-commerce (e.g., [2,3]). If delivery speed and quality that customers are used to today are to be maintained in the future, innovations are needed on the last-mile. On the other hand, the firms face a trade-off between routing efficiency and consumer convenience, leading to high costs, estimated to account for up to $30 \%$ of total distribution costs [4]. In this context, logistics service providers (LSP) and e-tailers are constantly looking for new ideas to overcome the described challenges. This dynamic, competitive environment has already led to several promising innovations that have been introduced to the market. However, it is not only technological maturity or financial considerations (e.g., [5,6]) but also user acceptance that determines market success. In recent years, this has motivated initial empirical studies to identify significant factors that influence consumer acceptance and adoption (e.g., $[4,7,8])$. However, in practice, many consumers are still hesitant to take advantage of the newly available delivery options and rely on the good old attended home deliveries.

Parcel lockers are the best example of this. Although DHL introduced the concept in Germany more than 20 years ago and $90 \%$ of the population can reach a parcel locker within less than ten minutes [9,10], it is still not widely used. So far, only 12 million Germans have signed up for the service and can use one of the 4000 parcel lockers available [11]. This corresponds to a share of less than $15 \%$ of the total population. Recently, DHL announced the expansion to 12,000 parcel lockers, which led to intense discussion and strong negative 
feedback on social media [12]. This is not an exclusive German issue. For Singapore, for instance, Choo [13] reported that only $5.5 \%$ of parcel deliveries are made to self-collection points. The examples point towards a current theory-practice gap, which raises why companies struggle to create alternative solutions on the last-mile successfully. Against this background, this study takes a step back in the research cycle, reviews the available literature, focuses on observations and patterns, and thus chooses an inductive qualitative research approach to answer the following research-leading question:

Which factors influence the intention to use selected last-mile, place-of-delivery innovations in a B2C context?

This paper contributes to the literature by providing a more structured and detailed understanding of what and how factors influence consumer acceptance for four alternative place-of-delivery innovations. In addition, the chosen comparative approach with multiple alternatives under investigation identifies differences, which can be used to derail innovation-specific research models and tailored communication and marketing strategies. Such knowledge is essential to better cope with the current challenges on the last-mile.

The following Section 2 introduces the investigated innovations, justifies the selection, and provides an overview of the available relevant literature. Section 3 introduces the methodology and presents the results. The results are then discussed in Section 4. Finally, the paper concludes with concluding remarks and an outlook in Section 5.

\section{Background}

Last-mile delivery can be defined as "[ . . ] all logistics activities related to the delivery of shipments to private customer households in urban areas" [14] (p. 2). Thus, the topic is grounded in the domain of urban freight transport. Over the past decades, multiple scholars have discussed the underlying planning processes and the need to understand how the multi-faceted needs of citizens can be met [15]. For a comprehensive literature review, please refer to Lindholm [16]. Recently, in light of the growing awareness of climate change, the need to consider not only economic but also environmental and societal effects gained importance $[15,17,18]$. This includes air pollution, greenhouse gas emissions, noise emissions, the use of land, traffic congestion, and traffic safety. Various authors highlighted that the growth in e-commerce is a main challenge and driver in urban freight transport $[10,14]$. The ever-increasing number of deliveries and returns will lead to even more delivery routes and vehicles on the last-mile, impacting a city's liveability and sustainability [15]. Therefore, alternative logistics services are necessary.

For that purpose, it is helpful to distinguish between the various configuration alternatives to investigate the last-mile adequately. One of the first works with an attempt to provide such typology is from Boyer et al. [19], who distinguished between (1) the semiextended supply chain (store as warehouse/distribution location and indirect delivery); (2) the decoupled supply chain (distribution center as warehouse/distribution location and indirect delivery); (3) the fully extended supply chain (store as warehouse/distribution location and direct delivery); and (4) the centralized extended supply chain (distribution center as warehouse/distribution location and direct delivery).

To more adequately reflect the last-mile's specific characteristics, Gevaers et al. [20] suggested a refined version, which has since become the arguably most commonly applied and cited typology. Starting from the storage-pick-up location of the supplier, they introduced the distinguishing criteria 'place of delivery' and 'type of delivery', and the 'specific solution'. However, their model does not consider current developments such as delivery robots or crowd delivery. Furthermore, the two criteria 'place of delivery' and 'type of delivery' are not mutually exclusive. For instance, they classified post offices as a type of delivery, although they could also be considered a place of delivery. Therefore, we adapted their typology to reflect better the transportation mode and the place of delivery as the two crucial design criteria [21]. In Figure 1, the four delivery innovations that this work examines are marked in bold. The following section justifies the selection and introduces those innovations in greater detail. 


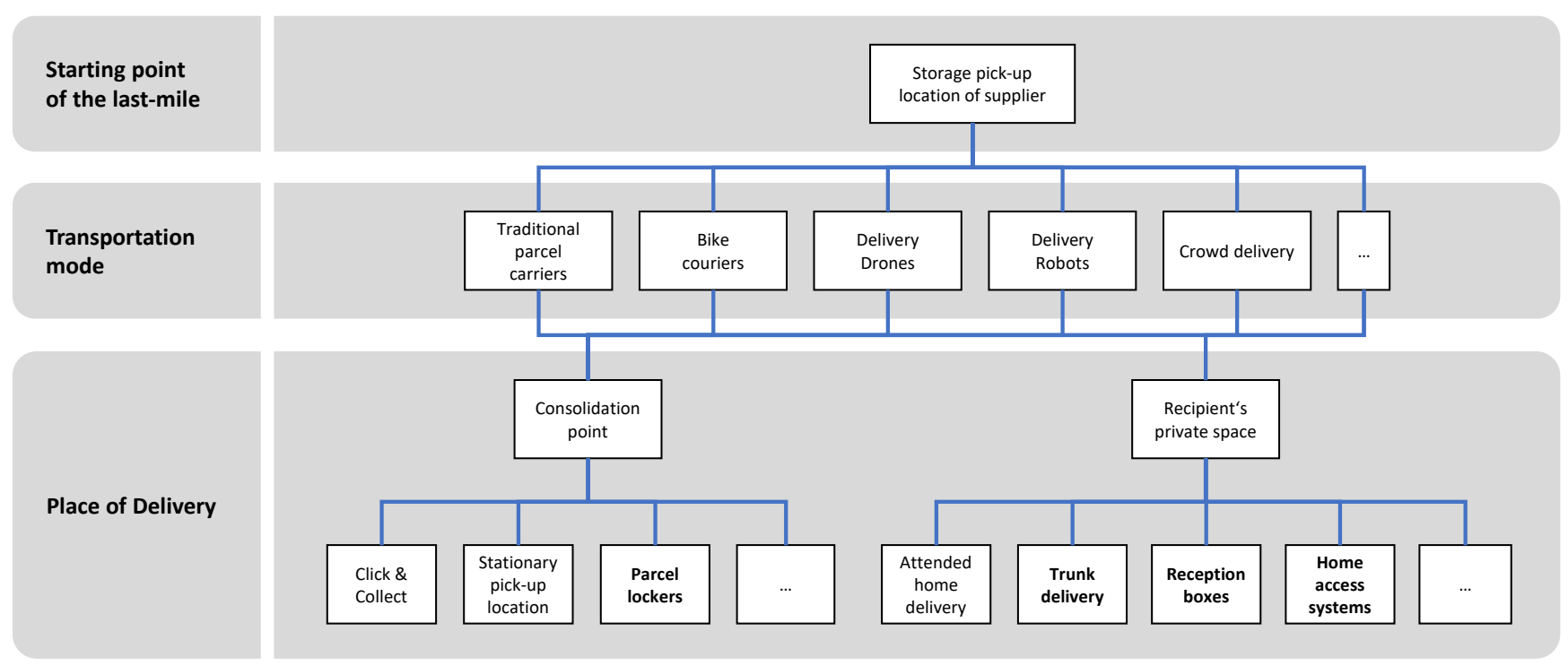

Figure 1. A refined last-mile typology based on Gevaers et al. (2011) [20].

\subsection{Place-of-Delivery Innovations}

As can be seen in the research question, this work focuses exclusively on the place-ofdelivery innovations, complementing existing qualitative work on alternative transportation modes, such as crowd delivery, delivery drones, and delivery robots [22]. While the LSP usually determines the transportation mode, customers specify the place of delivery via the provided delivery address. Therefore, the question of customer acceptance is of even greater importance. Mangiaracina et al. [23] conducted an exhaustive literature search and identified ten innovative solutions for the last-mile, four of which relate to the place of delivery. These are (1) parcel lockers, (2) reception boxes, (3) trunk delivery, and (4) pick-up points. The first three innovations are adopted for this study, while pick-up points are excluded due to the vast variability that might create some bias. For instance, pick-up points can be shops, petrol stations, or kiosks with different opening hours and other operating conditions, making the generalizability of an empirical investigation difficult. Instead, another innovation is considered, which was not mentioned in the literature review, but the leading e-commerce provider, Amazon, is currently pushing in the market: home access systems [24]. These innovations, introduced in more detail in the following sub-sections, have several benefits for the LSP. First, they increase the percentage of successful delivery attempts. Second, they enable flexible delivery times, allowing logistics firms to balance demand peaks better [25]. Third, they will allow optimized delivery routes. These advantages help reduce capacity problems and decrease the average costs per delivery. Besides, more efficient delivery also reduces the ecological footprint of e-commerce due to lower energy consumption and lower emissions (e.g., [26,27]).

\subsubsection{Parcel Locker}

A parcel locker is a group of publicly placed secure automated compartments that customers can use as a self-service delivery collection point instead of their home address [26]. To use parcel lockers, customers usually must register for the respective service [27]. When customers order packages to a parcel locker, the delivery company informs them as soon as the parcel has been placed in the locker and is available for pick-up, for example, via e-mail or text messaging [28]. Additionally, they are provided with a unique code to open the locker. Other services commonly available from parcel lockers are dispatching packages, return shipment services, and printing receipts. Depending on the respective business model, parcel lockers can either be used exclusively by a single company or can be made available for different carriers [26]. 


\subsubsection{Reception Box}

Privately-owned reception boxes resemble letterboxes but are big enough to fit packages. The boxes are attached to a customer's home (at the garage or in the garden) and are only accessible to people with the respective key or electronic code [29]. Customers can pick up the shipments at their convenience after the delivery company inserts packages into the box, similar to letterboxes [5]. The boxes vary in their design, for instance, regarding size and refrigeration capabilities, and costs. Usually, they are made of sturdy materials solidly fixed to the ground or a wall without a structural alteration [30]. Unlike the significantly larger, publicly accessible parcel lockers, they are owned or rented by the customer. In apartment buildings, shared reception boxes are possible.

\subsubsection{Trunk Delivery}

Trunk delivery is an innovation that gives delivery companies access to a vehicle's trunk as the desired drop-off point [31]. For that purpose, the parcel carrier locates the respective car with GPS and uses a time-limited access key to open the trunk. After the delivery, customers are notified and the temporary key expires. Technical prerequisites are that the car is accessible and within GPS reach. In general, the technology may be used to deliver and dispatch parcels [32].

\subsubsection{Home Access System}

Home access systems use smart locks to grant controlled access to the recipient's premises. Smart locks are Wi-Fi- or Bluetooth-based devices that operate doors by transmitting signals from mobile applications (e.g., tablets or smartphones) [30]. They typically also have recording capabilities. In general, home access systems function as follows: Upon arrival, the courier sends a request to the LSP or e-tailer to gain access. If granted, the courier gets a notification on a mobile device, the smart lock opens, and a camera starts recording. After that, the customer is notified of the successful delivery and a link to a video that shows the drop-off [24]. Initially, the idea of home access systems was to provide delivery services with actual access to the recipient's house or apartment. More recently, service providers began to focus on outbuildings such as garages. This type of home access system is the subject of this study.

\subsection{Empirical Literature on Consumer Acceptance of Last-Mile Place-of-Delivery Innovations}

Regardless of the innovation, consumer acceptance is essential for continued market success [33]. For this reason, it is worthwhile to review the literature published on this topic. For this purpose, a literature search was conducted on the most relevant databases (ScienceDirect, Business Source Premier, JSTOR, Web of Science), combining general search terms (last-mile, delivery, innovation) with the four innovations. Only empirical publications that contributed to understanding consumer acceptance of the investigated placeof-delivery innovations are considered in the following. It should be noted that there is further empirical work on consumer acceptance of alternative transportation modes such as delivery drones, robots, or crowdsourced delivery (e.g., [34-36]). However, these will not be further considered. As previously stated, this work focuses on place-of-delivery innovations, which, in contrast to alternative transportation modes, are determined by consumers when providing the delivery address during check-out.

Most extant studies are deductive and use structural equation modeling for data analysis. Table 1 documents those deductive quantitative empirical studies, the investigated factors, and the respective outcome variable. It shows that the majority referred to parcel lockers and were conducted in Asia. When comparing the commonalities, only a few factors have been replicated. These include the influence of 'convenience', 'perceived compatibility', 'security', 'privacy', and 'perceived relative advantage'. It should be noted that the mentioned studies did not derive their hypotheses from qualitative findings on place-of-delivery innovations but instead drew on more general studies on the acceptance of technologies or software. This points towards an existing research gap. In addition to 
the deductive quantitative empirical studies, only two qualitative ones are available. Due to their different methodological approach, they are not included in Table 1.

Table 1. Deductive quantitative empirical studies on the acceptance of place-of-delivery innovations.

\begin{tabular}{|c|c|c|c|c|c|}
\hline \multirow{2}{*}{ Study (Sample) } & \multirow{2}{*}{ Factor $\rightarrow$ Influence Variable (Effect Direction) } & \multicolumn{4}{|c|}{ Innovation } \\
\hline & & PL & RB & TD & HAS \\
\hline $\begin{array}{l}\text { Goethals et al. [7]; } n=245 \\
\text { consumers in France }\end{array}$ & Age $\rightarrow$ Interest in unattended home delivery (inverse U-shaped) & & $\sqrt{ }$ & & \\
\hline \multirow{4}{*}{$\begin{array}{l}\text { Chen et al. [8]; } n=281 \\
\text { consumers from China }\end{array}$} & Location convenience $\rightarrow$ Intention to use $(+)$ & $\sqrt{ }$ & & & \\
\hline & Need for human interaction $\rightarrow$ Intention to use $(+)$ & $\sqrt{ }$ & & & \\
\hline & Optimism $\rightarrow$ Intention to use $(+)$ & $\sqrt{ }$ & & & \\
\hline & Innovativeness $\rightarrow$ Intention to use $(+)$ & $\sqrt{ }$ & & & \\
\hline \multirow{4}{*}{$\begin{array}{l}\text { Wang et al. [33]; } n=170 \\
\text { consumers from Singapore }\end{array}$} & Perceived compatibility $\rightarrow$ Attitude $(+)$ & $\sqrt{ }$ & & & \\
\hline & Perceived complexity $\rightarrow$ Attitude (-) & $\sqrt{ }$ & & & \\
\hline & Perceived trialability $\rightarrow$ Attitude $(+)$ & $\sqrt{ }$ & & & \\
\hline & Perceived relative advantage $\rightarrow$ Intention to use $(+)$ & $\sqrt{ }$ & & & \\
\hline \multirow{6}{*}{$\begin{array}{l}\text { Yuen et al. [37]; } n=230 \\
\text { consumers from China }\end{array}$} & Convenience $\rightarrow$ Perceived value of innovation $(+)$ & $\sqrt{ }$ & & & \\
\hline & Privacy/Security $\rightarrow$ Perceived value of innovation $(+)$ & $\sqrt{ }$ & & & \\
\hline & Reliability $\rightarrow$ Perceived value of innovation (+) & $\sqrt{ }$ & & & \\
\hline & Convenience $\rightarrow$ Transaction cost of innovation $(+)$ & $\sqrt{ }$ & & & \\
\hline & Privacy/Security $\rightarrow$ Transaction cost of innovation $(+)$ & $\sqrt{ }$ & & & \\
\hline & Reliability $\rightarrow$ Transaction cost of innovation $(+)$ & $\sqrt{ }$ & & & \\
\hline \multirow{3}{*}{$\begin{array}{c}\text { Felch et al. [4]; } n=207 \\
\text { consumers from Germany }\end{array}$} & Usefulness $\rightarrow$ Willingness to test $(+)$ & & $\sqrt{ }$ & $\sqrt{ }$ & $\sqrt{ }$ \\
\hline & Security $\rightarrow$ Willingness to test $(+)$ & & $\sqrt{ }$ & $\sqrt{ }$ & $\sqrt{ }$ \\
\hline & Privacy $\rightarrow$ Willingness to test $(+)$ & & $\sqrt{ }$ & $\sqrt{ }$ & $\sqrt{ }$ \\
\hline \multirow{3}{*}{$\begin{array}{l}\text { Wang et al. [38]; } n=209 \\
\text { consumers from Singapore }\end{array}$} & Perceived relative advantage $\rightarrow$ Attitude $(+)$ & $\sqrt{ }$ & & & \\
\hline & Perceived relative advantage $\rightarrow$ Intention to use $(+)$ & $\sqrt{ }$ & & & \\
\hline & Perceived compatibility $\rightarrow$ Attitude $(+)$ & $\sqrt{ }$ & & & \\
\hline
\end{tabular}

Legend: $\mathrm{PL}=$ parcel locker, $\mathrm{RB}=$ reception box, $\mathrm{TD}=$ trunk delivery, $\mathrm{HAS}=$ home access system.

Vakulenko et al. [39] used a focus group technique with 26 participants from Sweden to gain insights on customer value relating to parcel lockers. They identified functional value (e.g., location or accessibility), emotional value (e.g., stress, fun), social value (e.g., less interaction), and financial value (e.g., cost savings) as pivotal influences. Buldeo Rai et al. [40] also referred to a focus group with 49 Dutch-speaking customers in Belgium to explore the customer's perception of home access and trunk delivery systems that use smart locks. The results indicate that the interviewed consumers strongly prefer home delivery and are frustrated about delivery failures. Their work focuses on the smart locks' potential without deriving specific variables or a research model. With their rather broad perspective, they noted that the perception of smart locks is primarily influenced by practical implications, risks, and security issues. They conclude that "[ ... ] support for smart locks among consumers seems limited" [40] (p. 5). The only two qualitative studies show that research is still in its infancy, particularly regarding reception boxes, trunk delivery, and home-access systems.

In summary, the findings present a fragmented picture. At this point, it is not possible to conclude (1) which specific factors need to be taken into account to achieve the highest possible customer acceptance for the four innovations under investigation, (2) whether the acceptance factors differ concerning the respective innovation, and (3) whether there are regional differences. These existing knowledge gaps motivate the collection of own data. 
Understanding which factors affect consumer acceptance are necessary for any demand model in urban freight planning [41]. According to Comi [15] (p. 1), such "[ ... ] demand models play a key role in support decision making". The conducted qualitative study is described in the following section.

\section{Qualitative Study}

\subsection{Data Collection Methodology}

As the data-collection method, this study used semi-structured interviews that followed an interview guide while allowing for additional questions at any time. At the beginning of each interview, standard delivery in the form of a postman delivering parcels to one's doorstep was introduced as the baseline for the innovations queried in the following. The questions were derived based on the development guidelines suggested by Fishbein and Ajzen [42] since their Theory of Planned Behavior (TPB) is an often-used theoretical foundation to investigate the behavioral factors that influence the adoption of last-mile delivery innovations. Furthermore, the approach was chosen because the available reviewed studies show how vital attitudes and perceptions are for the intention to adopt and use a technology (e.g., [33,37,38,40]). Most notably, Wang et al. [33] compared the explanatory power of theoretical models that posit a direct relationship between the perceived characteristics of an innovation and the intention to use with others that consider mediation by the consumers' attitudes. They found that the latter outperformed the former, which justifies the selection of the TPB. The TPB extends the theory of reasoned action (TRA) to improve the explanatory power by adding 'perceived behavioral control' to the two existing constructs 'attitude towards the behavior' and 'subjective norms' as explanatory variables of 'behavioral intention'. The interview guide consisted of twelve mostly open-ended questions divided into four categories and summarized in Table 2. The interviews were conducted face-to-face, via telephone, or via Skype.

Table 2. Interview guide.

\begin{tabular}{|c|c|}
\hline Category & Questions \\
\hline Background & $\begin{array}{c}\text { What gender are you? Which age group do you belong to? } \\
\text { How frequently do you receive deliveries? }\end{array}$ \\
\hline $\begin{array}{l}\text { Behavioral outcomes as } \\
\text { the basis for a consumer's } \\
\text { attitude }\end{array}$ & $\begin{array}{l}\text { What do you see as advantages of this innovation? What } \\
\text { would persuade you to make use of the innovation? What } \\
\text { do you see as disadvantages of the innovation? What } \\
\text { speaks against the use of the innovation? What else comes } \\
\text { to mind when you think about the innovation? }\end{array}$ \\
\hline Normative referents & $\begin{array}{c}\text { Which individuals or groups would like to use this } \\
\text { innovation? Which individuals or groups would disapprove } \\
\text { of the innovation? }\end{array}$ \\
\hline Control factors & $\begin{array}{l}\text { What factors or circumstances are there that would make it } \\
\text { easy to use this innovation? What factors or circumstances } \\
\text { are there that would make it difficult to use this innovation? }\end{array}$ \\
\hline
\end{tabular}

\subsection{Sampling}

In this study, a maximum variation sampling strategy is used [43]. Participants of different ages and with different ordering behaviors were recruited to reflect the diversity of potential parcel consignees. The process began with a research assistant's network and then used a snowballing technique, i.e., participants were asked to name someone they knew who would like to participate in the study. In total, 37 interviews were conducted before the current COVID-19 pandemic in late 2019. A total of 9 interviews referred to parcel lockers, 9 to reception boxes, 10 to trunk delivery, and 9 to home access systems. After the mutual introduction and the explanation of the baseline example, the average effective interview length was, on average, $22 \mathrm{~min}$ ( $\mathrm{min}$ : $17 \mathrm{~min}$, max: $37 \mathrm{~min}$ ). Initially, the goal was to conduct at least seven interviews for each innovation to ensure that enough insights would be available 
to account for the multi-faceted nature of the investigated problem. While there are differences to the interviews conducted in this study, Eisenhardt [44] used a similar line of argument in the context of case study research: "With fewer than 4 cases, it is often difficult to generate theory with much complexity [ ... ]. With more than 10 cases, it quickly becomes difficult to cope with the complexity and volume of the data" [44] (p. 545).

After reaching the minimum number of seven, further interviews were conducted until data saturation was reached. That is, no new influencing factors were mentioned in two consecutive interviews. Twenty-nine (78\%) of the interviews were with German consumers, complemented by $8(22 \%)$ additional ones with U.S.-American consumers. Most of the interviewees were female (65\%), which reflects the previously reported gender gap in online shopping (e.g., $[45,46])$. On average, the participants were 36 years old (range: 25-60 years) and had sufficient experience in online shopping. All the respondents receive e-commerce deliveries at least once every six months and $42 \%$ even at least once a month (range: more than once a week-once every six months).

\subsection{Data Analysis Methodology}

As data analysis method, this research refers to the deductive category development described in Mayring [47]. Thus, previously formulated, theoretically derived categories are brought into connection with the qualitative data. Mayring [47] structured the research process in six stages: (1) research question(s); (2) theory-based definition of the aspects of analysis and the main categories; (3) theory-based formulation of the definitions, examples and coding rules for the categories; (4) revision of the categories and coding agenda; (5) final working through of the texts; (6) interpretation of the results and quantitative steps of analysis (e.g., frequencies).

Regarding the first step, the research question was formulated in the introduction of this paper. For the second step, this research refers to the TPB, which is based on the work of Ajzen [48]. It posits that behavioral intention is the most important determinant of behavior. Behavioral intention, which comprises the desire and belief to perform a behavior, is influenced by: (1) the attitude towards the behavior, (2) the perceived subjective norms, and (3) the perceived behavioral control. The three overarching factors corresponded to the general structure of the interview guide. A coding agenda was set up and used to code the interviews in the third and fourth steps. During this initial coding, several codes were adapted and added. The first round of coding took place in February 2020. Then, in the fifth step, the final agenda was used to go over the data again. To increase the reliability of the data analysis and reduce potential temporal influences, the final round of coding was performed four months later, in June 2020. A comparison between the two rounds showed agreement for $92.5 \%$ of all the codes. The discrepancies between the coding rounds were analyzed, and a decision was made to keep, change or discard the code. The results (step 6) are sets of outcomes, normative referents, control factors, and additionally reported influences that are not addressed in the TPB, which will be reported after describing the sampling process. Figure 2 summarizes the research process.

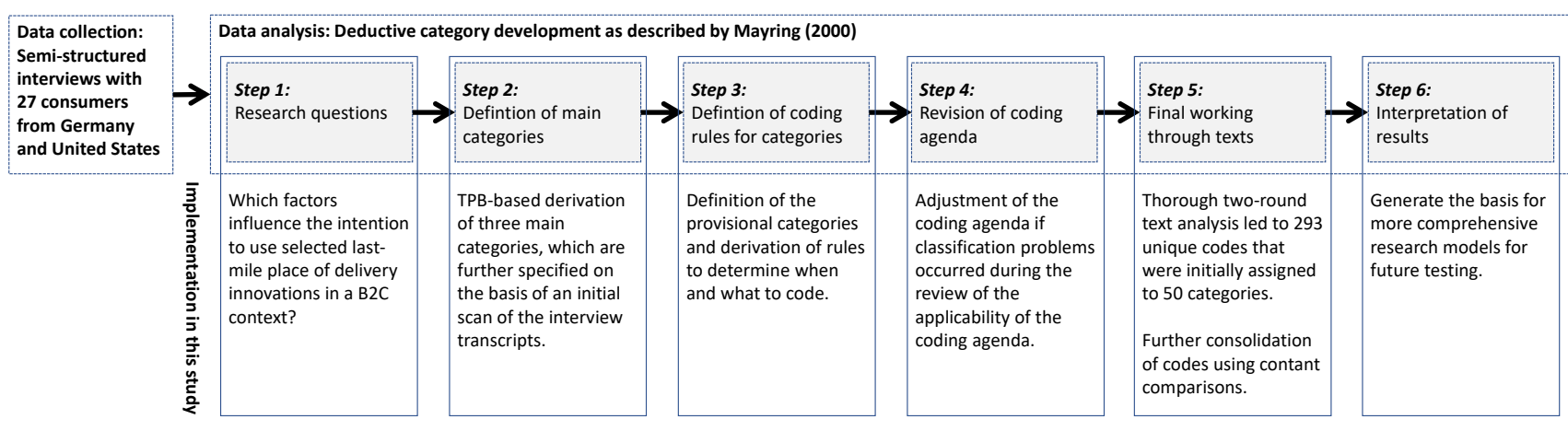

Figure 2. The research process. 


\subsection{Rigor, Validity, and Reliability}

In general, academic rigor is a way to create trust in the findings of a study. To demonstrate rigor in a qualitative study, Silverman [49] noted the importance of consistency and suggested five suitable strategies in qualitative research: (1) refutational analysis, (2) constant data comparison, (3) comprehensive data use, (4) inclusive of the deviant case and (5) use of tabulations. Table 3 summarizes the measures taken in this study.

Table 3. Measures to ensure rigor, adapted from Silverman [49].

\begin{tabular}{|c|c|c|}
\hline Measure & Purpose & Strategy Applied in the Study \\
\hline Refutational analysis & $\begin{array}{c}\text { Deliberately explore potential contradictions } \\
\text { between individual cases to increase objectivity. }\end{array}$ & $\begin{array}{l}\text { Apart from the used interview guide, } \\
\text { specific follow-up questions were asked } \\
\text { to investigate the context further and } \\
\text { identify potential deviations. }\end{array}$ \\
\hline Constant data comparison & $\begin{array}{l}\text { Inspect and compare all data fragments that arise in } \\
\text { every single case to test provisional hypotheses and } \\
\text { attribute relevance. }\end{array}$ & $\begin{array}{l}\text { Contant review of the coding agenda. } \\
\text { Multiple coding rounds with a high } \\
\text { agreement rate }(>90 \%) \text { were performed. }\end{array}$ \\
\hline Comprehensive data use & $\begin{array}{l}\text { Address anecdotalism by performing } \\
\text { in-depth analysis. }\end{array}$ & $\begin{array}{l}\text { Interviews were transcribed and } \\
\text { analyzed during the data collection } \\
\text { process to allow for and ensure } \\
\text { data saturation. }\end{array}$ \\
\hline Inclusive of the deviant case & $\begin{array}{l}\text { Test the theory choosing an extreme case to allow } \\
\text { for generalizations. }\end{array}$ & $\begin{array}{l}\text { Interviews with consumers from different } \\
\text { markets (Germany, United States of } \\
\text { America) and consideration of different } \\
\text { age groups (oldest participant } 60 \text { years } \\
\text { old) were conducted. }\end{array}$ \\
\hline Use of tabulations & $\begin{array}{l}\text { Improve the quality of data analysis by highlighting } \\
\text { the relevance and providing another perspective on } \\
\text { the data collected. }\end{array}$ & $\begin{array}{l}\text { Integration of quantitative analysis } \\
\text { through frequency tables } \\
\text { (see Tables 5-9). }\end{array}$ \\
\hline
\end{tabular}

Another crucial dimension regarding the quality of a qualitative study is validity. According to Krippendorff [50] (p. 313), validity is what "[ ... ] leads us to accept [results] as true, as speaking about the real world of people, phenomena, events, experiences, and actions". This study employed several techniques during the data collection and analysis to ensure the truthfulness of the presented results. For instance, a theoretical sampling approach was used that refers to data saturation instead of a fixed sample size. Semantic validity was addressed during the development and improvement of the coding agenda. Furthermore, direct quotations from the interviews were used to underpin the argumentation.

The research process must not only address validation efforts but also be considered reliable. In quantitative empirical research, reliability refers to the exact replicability of the results. However, in the qualitative research paradigm, which accepts multiple realities and hence refers more to interpretation and individual assessments, it is difficult to provide a generally accepted definition, if not epistemologically self-contradictory. As a reaction to those peculiarities, Lincoln and Guba [51] created a set of four trustworthiness criteria. To be considered trustworthy and thus reliable, a study must ensure (1) credibility, (2) dependability, (3) transferability, and (4) confirmability. Table 4 summarizes the measures taken to increase the reliability of this study. Based on the efforts made, there can be confidence that a rigorous research process led to valid and reliable results, presented in the following section. 
Table 4. Measures to ensure reliability, adapted from Lincoln and Guba [51].

\begin{tabular}{|c|c|c|}
\hline Measure & Purpose & Strategy Applied in the Study \\
\hline Credibility & $\begin{array}{l}\text { Establish confidence that the results are } \\
\text { true and believable. }\end{array}$ & $\begin{array}{l}\text { As the study advanced, we tried to confirm each } \\
\text { relevant factor against at least one other interview } \\
\text { and the available literature. }\end{array}$ \\
\hline Dependability & $\begin{array}{c}\text { Ensure that the findings are repeatable if } \\
\text { the inquiry occurred within the same } \\
\text { sample, coders, and context. }\end{array}$ & $\begin{array}{l}\text { A clear description of the research process and } \\
\text { application of multiple coding rounds with high } \\
\text { agreement rates }(>90 \%) \text {. }\end{array}$ \\
\hline Transferability & $\begin{array}{c}\text { Increase the degree to which the results } \\
\text { can be generalized and applied to } \\
\text { other contexts. }\end{array}$ & $\begin{array}{l}\text { Interviews were performed with consumers from } \\
\text { two different markets with different } \\
\text { cultural backgrounds. }\end{array}$ \\
\hline Confirmability & $\begin{array}{c}\text { Ensure that the interpretations are in fact } \\
\text { derived from the data. }\end{array}$ & $\begin{array}{c}\text { Quantification of the analysis through the use } \\
\text { of tabulations. }\end{array}$ \\
\hline
\end{tabular}

\subsection{Results}

In general, the largest proportion of interviewees (43\%) was somewhat skeptical about the place-of-delivery innovations. However, the individual innovations differ considerably (see Table 5).

Table 5. General evaluation of innovations.

\begin{tabular}{ccccc}
\hline Evaluation & PL $(n=9)$ & RB $(n=9)$ & TD $(n=10)$ & HAS $(n=9)$ \\
\hline Positive $(n=10 ; 27 \%)$ & $n=4(44 \%)$ & $n=5(56 \%)$ & $n=1(10 \%)$ & $n=0(0 \%)$ \\
\hline Neutral $(n=11 ; 30 \%)$ & $n=4(44 \%)$ & $n=4(44 \%)$ & $n=1(10 \%)$ & $n=2(22 \%)$ \\
\hline Negative $(n=16 ; 43 \%)$ & $n=1(11 \%)$ & $n=0(0 \%)$ & $n=8(80 \%)$ & $n=7(78 \%)$ \\
\hline Legend: PL = parcel locker, RB = reception box, TD = trunk delivery, HAS $=$ home access system.
\end{tabular}

The participants appeared interested in parcel lockers and reception boxes. In contrast, trunk delivery and home access systems were rejected. Some participants were so vehemently opposed that they found it difficult to name any advantages of the solution discussed. Several respondents answered "nothing" with regard to home access systems when asked what would persuade them to use the innovation. Some of the concerns expressed took on irrational dimensions, as the following quotation regarding trunk delivery shows: "I don't expect them to plant an explosive device, but it's enough that they somehow get into my private space. They might as well put a listening device or whatever. And what if they do it to everyone". Furthermore, all the interviews documented a very high level of satisfaction with the standard attended home delivery. Given the high expectations, it appears challenging to establish new concepts.

Hence, it is even more critical to identify the factors that influence the intention to adopt a technology as a basis for broader consumer acceptance. The previously described coding process resulted in 293 codes first assigned to 50 unique categories. Later, those initial categories were further condensed to 41 categories based on contextual similarity. To remain focused and to ensure credibility, only the 22 categories found in at least two interviews are considered in the following.

\subsubsection{Attitude towards the Place-of-Delivery Innovation}

Ajzen (1991) defined attitude as "[ ... ] the degree to which a person has a favorable or unfavorable evaluation or appraisal of the behavior in question" [48] (p. 188). Therefore, the consumers' behavioral outcomes were queried to study the attitude towards the respective place-of-delivery innovation in more detail. The subsequent coding focused on affective and cognitive remarks (see Table 6). 
Table 6. Mentioned behavioral outcomes.

\begin{tabular}{ccccc}
\hline Outcomes & PL $(n=9)$ & RB $(n=9)$ & TD $(n=10)$ & HAS $(n=9)$ \\
\hline Increased flexibility * $(n=28 ; 76 \%)^{*} n=8(89 \%)$ & $n=7(78 \%)$ & $n=9(90 \%)$ & $n=4(44 \%)$ \\
\hline Better reliability * $(n=27 ; 73 \%)$ & $n=7(78 \%)$ & $n=7(78 \%)$ & $n=8(80 \%)$ & $n=5(56 \%)$ \\
\hline Higher independence * $(n=21 ; 57 \%)$ & $n=6(67 \%)$ & $n=6(67 \%)$ & $n=6(60 \%)$ & $n=3(33 \%)$ \\
\hline Safer shipment storage * $(n=11 ; 30 \%)$ & $n=4(44 \%)$ & $n=2(22 \%)$ & $n=2(20 \%)$ & $n=3(33 \%)$ \\
\hline Time savings ** $(n=7 ; 19 \%)$ & $n=1(11 \%)$ & $n=0(0 \%)$ & $n=4(40 \%)$ & $n=2(22 \%)$ \\
\hline More convenience * $(n=5 ; 13 \%)$ & $n=0(0 \%)$ & $n=1(11 \%)$ & $n=2(20 \%)$ & $n=2(22 \%)$ \\
\hline Lower costs ** $(n=3 ; 8 \%)$ & $n=2(22 \%)$ & $n=0(0 \%)$ & $n=1(10 \%)$ & $n=0(0 \%)$ \\
\hline
\end{tabular}

Legend: PL $=$ parcel locker, $\mathrm{RB}=$ reception box, TD $=$ trunk delivery, HAS $=$ home access system,${ }^{*}=$ performance expectancy, ${ }^{* *}=$ effort expectancy.

Most participants expect 'increased flexibility' regarding the delivery and pick-up times, 'better reliability', that is, fewer unsuccessful delivery attempts, and 'higher independence' from neighbors. For instance, one interviewee noted: "Also, no neighbor has to accept the package, for example. Neighbors won't even know you ordered anything." Other factors such as 'safer shipment storage' or 'time savings' appear less critical. In addition, the identified behavioral outcomes are very similar across all four innovations. The relevant factors can be further classified depending on whether they are more likely to affect performance or effort expectations, showing a clear preference for performance expectations.

\subsubsection{Subjective Norms Regarding the Place-of-Delivery Innovation}

According to Ajzen (1991), subjective norms refer "[ .. ] to the perceived social pressure to perform or not to perform the behavior" [48] (p. 188). Although 'social pressure' appears to have a negative connotation, it can also manifest as positive reinforcement that motivates behavior [52]. People then use an alternative because others think positively about it.

Subjective norms are formed by relevant normative referents, which were addressed during the interviews. Numerous participants responded to the question in a generalizing manner. In the case of more positively perceived innovations, such as $\mathrm{PL}$, the question concerning which people would use this innovation was answered multiple times with "everybody". In contrast, some responded to the question of negatively perceived innovations with "nobody". This includes family and friends as the most typical referents. In response to a follow-up question, reference was frequently made to more specific groups (see Table 7). The most commonly mentioned are working people ('employees'), which refers to colleagues as another large group of normative referents. In addition, 'frequent travelers' were mentioned. As travel is often work-related, there is an overlap with employees. Regarding 'disabled people', there was one assessment that they could benefit from home access systems and support them. In contrast, they would reject parcel lockers because of the often-limited mobility. In brief, the conducted research indicates that the perceived support of family, friends, and colleagues may influence the intention to use such an innovation. Other normative referents appear somewhat irrelevant.

Table 7. Specifically mentioned normative referents.

\begin{tabular}{ccccc}
\hline Normative Referents & PL $(n=9)$ & RB $(n=9)$ & TD $(n=10)$ & HAS $(n=9)$ \\
\hline Employees $(n=17 ; 46 \%)$ & $n=8(89 \%)$ & $n=3(33 \%)$ & $n=3(30 \%)$ & $n=3(33 \%)$ \\
\hline Frequent travelers $(n=12 ; 32 \%)$ & $n=5(56 \%)$ & $n=3(33 \%)$ & $n=2(20 \%)$ & $n=2(22 \%)$ \\
\hline Disabled people $(n=2 ; 5 \%)$ & $n=1(11 \%)$ & $n=0(0 \%)$ & $n=0(0 \%)$ & $n=1(11 \%)$
\end{tabular}

Legend: $\mathrm{PL}=$ parcel locker, $\mathrm{RB}$ = reception box, TD = trunk delivery, HAS = home access system. 


\subsubsection{Subjective Norms Regarding the Place-of-Delivery Innovation}

Even though perceived behavioral control was initially introduced as a unitary construct [48], there is a growing consensus that it consists of two dimensions: (1) self-efficacy and (2) controllability [53]. In the context of selecting a place-of-delivery innovation, self-efficacy is referred to as the extent to which a consumer perceives the ease or difficulty and has the confidence to use a specific innovation [54]. Controllability refers to anticipated situational impediments and obstacles [53].

The study participants were remarkably willing to provide information on the circumstances that make it easy or difficult to use a place-of-delivery innovation. 'Safety/security/ liability' and 'spatial impediments' were the most frequently mentioned, followed by 'data protection/privacy' and 'car access/ownership' (see Table 8).

Table 8. Identified behavioral control factors.

\begin{tabular}{|c|c|c|c|c|}
\hline Control Factors & PL $(n=9)$ & $\mathrm{RB}(n=9)$ & $\operatorname{TD}(n=10)$ & HAS $(n=9)$ \\
\hline Security/liability $(n=20 ; 54 \%)$ & $n=0(0 \%)$ & $n=5(56 \%)$ & $n=9(90 \%)$ & $n=6(67 \%)$ \\
\hline Spatial impediments $(n=20 ; 54 \%)$ & $n=7(78 \%)$ & $n=8(89 \%)$ & $n=5(50 \%)$ & $n=0(0 \%)$ \\
\hline $\begin{array}{l}\text { Data protection/privacy } \\
\qquad(n=14 ; 38 \%)\end{array}$ & $n=1(11 \%)$ & $n=1(11 \%)$ & $n=8(80 \%)$ & $n=4(44 \%)$ \\
\hline $\begin{array}{l}\text { Mobility/car ownership } \\
\qquad(n=14 ; 38 \%)\end{array}$ & $n=4(44 \%)$ & $n=0(0 \%)$ & $\begin{array}{l}n=10 \\
(100 \%)\end{array}$ & $n=0(0 \%)$ \\
\hline $\begin{array}{l}\text { Technical reliability/functionality } \\
\qquad(n=9 ; 24 \%)\end{array}$ & $n=3(33 \%)$ & $n=1(11 \%)$ & $n=4(40 \%)$ & $n=1(11 \%)$ \\
\hline $\begin{array}{l}\text { Acquisition/operating costs } \\
\qquad(n=8 ; 22 \%)\end{array}$ & $n=0(0 \%)$ & $n=7(78 \%)$ & $n=0(0 \%)$ & $n=1(11 \%)$ \\
\hline Trustworthiness $(n=8 ; 22 \%)$ & $n=0(0 \%)$ & $n=1(11 \%)$ & $n=3(30 \%)$ & $n=4(44 \%)$ \\
\hline $\begin{array}{l}\text { Perceived additional effort } \\
\qquad(n=6 ; 16 \%)\end{array}$ & $n=5(56 \%)$ & $n=0(0 \%)$ & $n=1(10 \%)$ & $n=0(0 \%)$ \\
\hline Real estate ownership $(n=6 ; 16 \%)$ & $n=0(0 \%)$ & $n=3(33 \%)$ & $n=0(0 \%)$ & $n=3(33 \%)$ \\
\hline $\begin{array}{l}\text { Shipment-related impediments } \\
\qquad(n=5 ; 13 \%)\end{array}$ & $n=3(33 \%)$ & $n=1(11 \%)$ & $n=1(10 \%)$ & $n=0(0 \%)$ \\
\hline $\begin{array}{l}\text { Affinity for technological progress } \\
\qquad(n=3 ; 8 \%)\end{array}$ & $n=0(0 \%)$ & $n=0(0 \%)$ & $n=1(10 \%)$ & $n=2(22 \%)$ \\
\hline
\end{tabular}

Legend: $\mathrm{PL}=$ parcel locker, $\mathrm{RB}=$ reception box, $\mathrm{TD}=$ trunk delivery, $\mathrm{HAS}=$ home access system.

The relevant factors differ significantly depending on the innovation. For example, the respondents do not question the security of parcel lockers, which therefore does not play a role. However, it is highly relevant for the others: "So safety is a big issue. Because you really have to make sure that he can only go into the garage and not maybe into the house and then just this one time. And that nobody can abuse it". In the interviews, some participants mentioned providing detailed, verifiable information as one way to create a feeling of security, as illustrated by the following quotation: "Well, I'd need more information about [the safety standards in place]. Then I could say that I'm using it". Another approach would be to have the security certified by external institutions. This could include disclosure of the source code of the software used to allow independent third-party verification.

For parcel lockers, the spatial requirements refer to the proximity to the next locker; for reception boxes, to the space for installing such a box; and for trunk delivery, to the accessibility of the car, such as if the vehicle is parked in a private parking lot. Data protection and privacy are particularly relevant with regard to trunk delivery and home access systems. The participants point out two factors: (1) the possible intrusion of a private area: "I guess for me, I would not want them to get access to my stuff"; (2) potential permanent tracking and monitoring, especially with regard to trunk delivery. Nevertheless, a respondent realized that this could be a false apprehension of trunk delivery because 
this is already given by built-in technologies in the cars: "[...] I suppose that's generally already given; all this stuff is already built-in [in cars]. [...] You just don't know what will happen with the dat $a^{\prime \prime}$. The fundamental prerequisite for using trunk delivery is a car, or as one participant puts it: "And you definitely need a car. What about people who don't have cars?" Thus, the high number of references is not surprising but instead indicates data quality. Much less relevant appear to be 'technical reliability/functionality', 'acquisition/operating costs', an innovation's 'trustworthiness', 'real estate ownership', and 'shipment-related impediments', with some factors standing out for individual innovations. For instance, acquisition and operating costs refer to the necessary investments to install and maintain reception boxes. Interestingly, these are not mentioned nearly as frequently with regard to trunk delivery and home access systems.

\subsubsection{Other Reported Influences}

In addition, the interviews revealed influences that are not addressed in the TPB (see Table 9). For example, several participants repeatedly refer to one's 'safety consciousness', which can be described as someone avoiding risky activities, as a factor that they think is decisive in adopting trunk delivery or home access systems. In addition, there are multiple references to age. The participants commented that either younger consumers would resort to such an innovation or older consumers would refrain from doing so. While these factors need to be further explored in future research, the interviews suggest a moderating role in how it changes the nature of the relationship between the attitude towards the innovation and the intention to use it: "Probably just suspicious people. Yes. I think even old people would be afraid of someone coming in there. I think it's also a bit of a personality thing. [ ... ] Even though they might actually like the idea of such systems, I think there is little chance that they will use it."

Table 9. Other influences.

\begin{tabular}{ccccc}
\hline Other Factors & PL $(n=9)$ & RB $(n=9)$ & TD $(n=10)$ & HAS $(n=9)$ \\
\hline Safety consciousness $(n=16 ; 43 \%)$ & $n=1(11 \%)$ & $n=0(0 \%)$ & $n=9(90 \%)$ & $n=6(60 \%)$ \\
\hline Age $(n=10 ; 27 \%)$ & $n=5(56 \%)$ & $n=1(11 \%)$ & $n=2(20 \%)$ & $n=2(22 \%)$ \\
\hline Legend: PL = parcel locker, RB = reception box, TD = trunk delivery, HAS = home access system.
\end{tabular}

\section{Discussion}

The study provides a previously unavailable detailed picture of which factors and how these factors influence consumer acceptance with regard to place-of-delivery innovations. A comparison with the literature review results confirms four of the five already replicated factors. Those are the influence of 'convenience', 'security', 'privacy' and 'perceived relative advantage'. Particular emphasis should be placed on the latter. Almost all respondents expressed their expectations based on the alternatives available and known to them. This comparative evaluation approach should be considered in future research to account for a potential intention-behavior gap, which refers to both initial adoption and long-term use [55]. Otherwise, despite an overall positive evaluation, intention can be a poor predictor of actual adoption behavior. In other words, consumers may not follow through with their intention because alternatives still allow a better satisfaction of their needs.

'Perceived compatibility', defined as " $[\ldots]$ the degree to which an innovation is perceived as being consistent with the existing values, needs, and past experiences of potential adopters" [38] (p. 1387), was not directly mentioned by participants. However, the identified expected behavioral outcomes (see Table 6) can be viewed as a specification of needs. In addition, the relevance of 'reliability' [37] and 'age' [7] was replicated for the first time. The factor 'innovativeness' [5] is similar to the 'affinity for technological progress' noted in this study. Furthermore, those factors that the participants did not mention are of interest.

These include the 'need for human interaction' [8], 'perceived trialability' [33], and 'perceived complexity' [33]. Even when directly asked, none of the participants implied that 
social contact was necessary or desired to use any innovation. One possible explanation for this is that social contact is minimal in Germany and the United States, even with a parcel carrier. One participant commented: "[...] because the social fuss is not huge these days anyway". 'Trialability' and 'complexity' were also not addressed. Apparently, the respondents do not expect any problems when using such a system for the first time and do not perceive the innovations as complex.

It should also be noted that all mentioned factors reflect a rather utilitarian motivation. In contrast, any form of hedonic motivation such as fun or joy [39] appears to be somewhat irrelevant when discussing place-of-delivery innovations. Finally, despite society's omnipresent discussion about sustainability, it is striking that only one of the participants even mentioned environmental issues. This indicates that consumers are unwilling to change their preferred place of delivery to support greener logistics practices.

The reviewed literature combined with the provided qualitative insights allows us to explain better what factors may be responsible for higher and lower levels of customer acceptance, as manifested in the intention to use and the actual use. Based on the study results and the general guidelines of the TPB and other theoretical behavioral approaches, concrete research models can be derived in an abductive reasoning effort. Such a model is exemplified for trunk delivery in Figure 3.

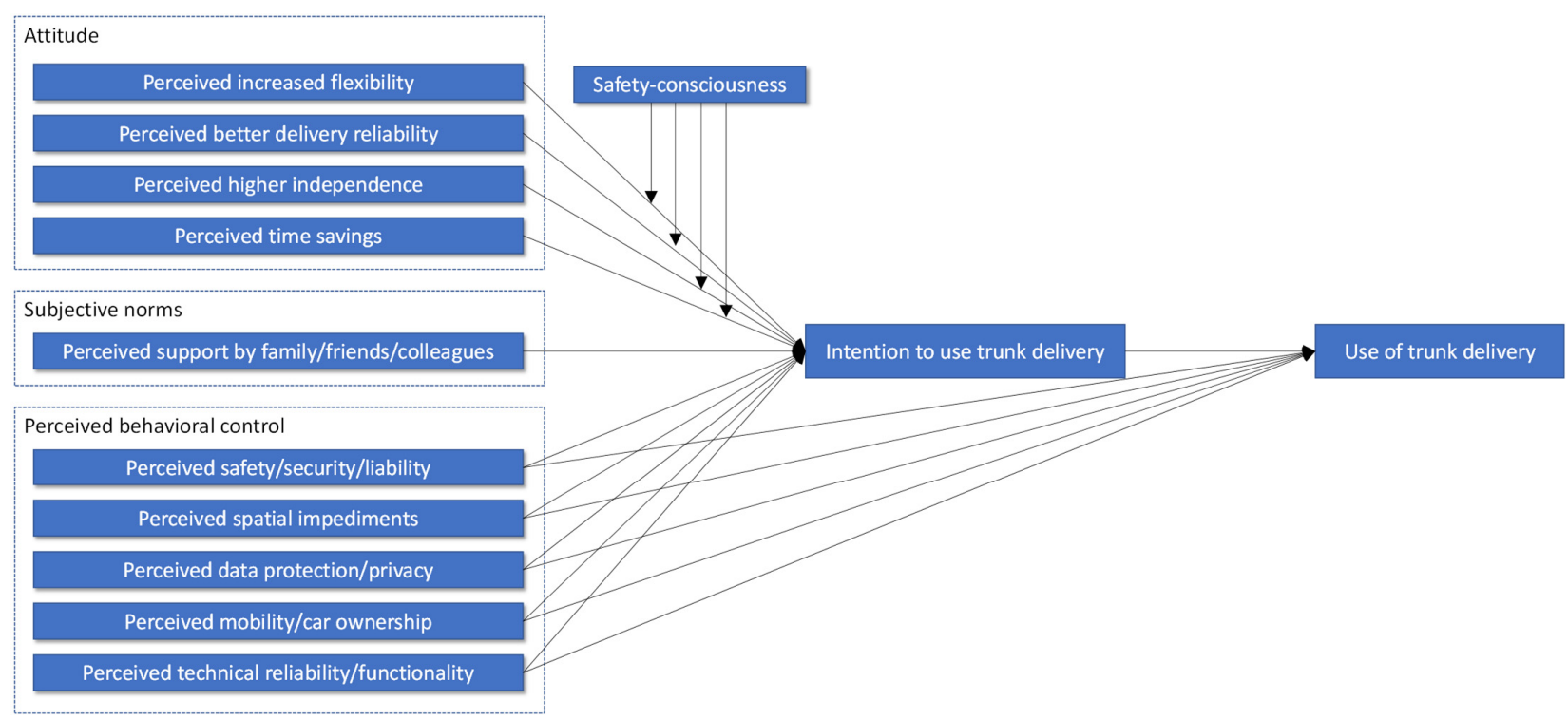

Figure 3. A derived research model for trunk delivery.

For clarity, only those factors were included that were mentioned in at least one-third of the interviews. Accordingly, the intention to use and, ultimately, the use of trunk delivery are positively influenced by the four factors that form the attitude towards the innovation (perceived increased flexibility, perceived better reliability, perceived higher independence, perceived time savings). These effects are stronger if someone's safety-consciousness is low (moderation effect). In addition, the extent to which someone believes that family, friends, or colleagues would approve of trunk delivery positively affects their intention to use the technology. The same effect applies to the five relevant behavioral controls; namely, the trunk delivery's perceived safety/security/liability, spatial impediments, data protection/privacy, mobility/car ownership, and technical reliability/functionality.

Comparing the factors that influence the intention to use a place-of-delivery innovation shows that there is only greater agreement on the behavioral outcomes. Thus, if the goal is to develop a holistic understanding, each innovation requires explicit research that considers its unique characteristics. Regional differences, however, do not seem to play a major role. Although the previous studies were primarily from Asia, only minor differences were discernible. This is also true within this study, which considered European and 
North American consumers. Participants from both groups provided answers with minor deviations. Accordingly, results appear to be comparatively robust, regardless of where the data is collected.

Finally, the findings challenge the often-expressed view that consumers generally prefer traditional attended home delivery in the form of carriers delivering packages to the front door (e.g., $[39,40])$. While their home might be the favored location, it is the reception box that many participants were very open-minded about. One participant noted: "I find this a total advantage because actually everything I wish for is fulfilled. The freedom of the person who receives the parcel, that is, if you are not there, it doesn't matter, because it will be delivered anyway and not returned. And you don't have a long way to go because it's right on your doorstep. So, I think that's really neat." Unfortunately, acquisition costs and spatial impediments prevent more widespread use. However, if, for instance, politics would oblige property owners to install such boxes in newly constructed buildings and conversions, this could lead to a market breakthrough. For this reason, the current dominance of attended home delivery is by no means set in stone. This would be good news not only for LSPs and e-tailers suffering from high costs and capacity issues but also for society, as it would enable greener delivery even without consumers directly aiming for it.

\section{Conclusions}

E-commerce grew in the past and will continue to grow even faster due to the current COVID-19 pandemic. This should please both e-tailers and LSPs, but at the same time it poses great challenges, especially on the last-mile. This paper reviews the extant literature and then conducts a qualitative study to explore which factors influence the acceptance of the four alternative place-of-delivery innovations. Those alternatives can make the last-mile more efficient, reduce the current capacity problems, and minimize the ecological burden of secondary delivery attempts.

So, what new do we know after reading this article, that is, what is the theoretical contribution? According to Whetten [56], the contribution of a study can arise from the four core building blocks of theory development: (1) the factors (variables, constructs, concepts) to explain the phenomenon of interest (what?), (2) the relationship between those factors (how?), (3) the logical justifications for altered views (why?), and (4) potential temporal and contextual features that limit generalizability (who?, where?, when?).

By confirming previously reported factors and identifying new factors, this study contributes to the first two fundamental building blocks (what?, how?) that allow for the derivation of innovation-specific research models. These insights lay the groundwork for subsequent confirmatory studies, particularly concerning the previously under-studied options of the reception box, trunk delivery, and home access systems. The comparative approach with multiple innovations also allows for a preliminary relative assessment of the factors' relevance. The study included participants from Europe and North America to investigate contextual influences, which is a further building block (where?). A comparison revealed no large differences, which is further strengthened by the observation that this research replicated several previously reported factors from studies conducted in Asia. Altogether, this is a strong indication of the results' generalizability. Thus, this study contributes to the urban freight transport literature. While previous studies focused on operational decision problems to be solved when setting up and operating alternative delivery concepts [10,14], this study contributes to the behavioral decision problems and reflects the consumer's perspective. Such knowledge is fundamental for the demand scenarios that are a prerequisite for research on urban transportation planning [41].

Managerially, this work gives practitioners a compact overview of the current state of research and provides additional insights into which factors may act as a lever to increase customer acceptance. LSPs, e-tailers, and start-ups can use the previously unavailable level of detail concerning the influencing factors of consumer acceptance to adapt and tailor their communication and marketing strategies by reinforcing the behavioral outcomes and addressing the identified behavioral controls. For instance, highlighting increased 
flexibility and reliability while providing transparency about safety precautions to create trust appears to be a promising approach. Such targeted strategies may even help the somewhat dated parcel lockers to achieve a broad market breakthrough finally.

From a societal perspective, all four innovations can increase the proportion of successful deliveries. Because delivery times often collide with working hours or other activities, delivery failure rates can be as high as $60 \%$ [40], resulting in more transports and emissions. An increase in consumer acceptance of alternative places of delivery, to which the results of this work may contribute, will help reduce the current challenges in various ways. First, it reduces logistics costs, which are a major determinant of prices in e-commerce. Second, it reduces traffic congestion, air pollution, greenhouse gas emissions, and noise emissions. Third, it reduces the risk of accidents. Altogether, the acceptance of alternative places of delivery would increase the sustainability of e-commerce in general and urban freight transport in particular, which is a crucial task in the future.

One of the limitations is that this research solely draws on the TPB. Other theoretical lenses, such as the Unified Theory of Adoption and Use of Technology (UTAUT), could be used [57]. Nonetheless, the results remain valuable because many behavioral theories share broad common ground. Besides, recent comparative research concludes that there is no superior behavioral theory but rather that the explanatory power depends on the subject under investigation [54]. Another limitation is that this study only focuses on place-of-delivery innovations while not considering transportation modes such as drone delivery or delivery robots. Although logistics providers rather than consumers determine the mode of transportation, future research could explore the acceptability of solutions for the entire last-mile that combine innovative modes of transportation with alternative delivery locations. Finally, we acknowledge that one may wonder whether parcel lockers are an innovation. Parcel lockers have indeed been around for some time. However, while such lockers themselves may not be technically new, they are new to a large portion of consumers who have not yet used them (e.g., $[11,13])$. Therefore, it is appropriate and essential to conduct such research to address the current last-mile challenge. Furthermore, we hope that it will motivate other scholars to build on it and contribute to the e-commerce supply chain of the future.

Funding: This research received no external funding.

Institutional Review Board Statement: Not applicable.

Informed Consent Statement: Not applicable.

Data Availability Statement: Available upon request in an anonymous form.

Acknowledgments: I would like to thank my student Lisa Niedermaier, who supported me with the data collection.

Conflicts of Interest: The author declares no conflict of interest.

\section{References}

1. BIEK. KEP-Studie 2019. Available online: https:/ / www.biek.de/download.html?getfile=2335 (accessed on 18 March 2021).

2. Kulkarni, S.R.; Barge, P. Effect of COVID-19 on the Shift in Consumer Preferences with Respect to Shopping Modes (Offline/Online) for Groceries: An Exploratory Study. Int. J. Manag. 2020, 11, 581-590.

3. Galhotra, B.; Dewan, A. Impact of COVID-19 on digital platforms and change in E-commerce shopping trends. In Proceedings of the 2020 Fourth International Conference on I-SMAC (IoT in Social, Mobile, Analytics and Cloud), Palladam, India, 7-9 October 2020; pp. 861-866.

4. Felch, V.; Karl, D.; Asdecker, B.; Niedermaier, A.; Sucky, E. Reconfiguration of the Last Mile: Consumer Acceptance of Alternative Delivery Concepts. In Logistics Management; Bierwirth, C., Kirschstein, T., Sackmann, D., Eds.; Springer International Publishing: Cham, Germany, 2019; pp. 157-171. ISBN 978-3-030-29820-3.

5. Punakivi, M.; Yrjölä, H.; Holmström, J. Solving the last mile issue: Reception box or delivery box? Int. J. Phys. Distrib. Logist. Manag. 2001, 31, 427-439. [CrossRef]

6. Punakivi, M.; Tanskanen, K. Increasing the cost efficiency of e-fulfilment using shared reception boxes. Int. J. Retail. Distrib. Manag. 2002, 30, 498-507. [CrossRef] 
7. Goethals, F.; Leclercq-Vandelannoitte, A.; Tütüncü, Y. French consumers' perceptions of the unattended delivery model for e-grocery retailing. J. Retail. Consum. Serv. 2012, 19, 133-139. [CrossRef]

8. Chen, Y.; Yu, J.; Yang, S.; Wei, J. Consumer's intention to use self-service parcel delivery service in online retailing. Internet Res. 2018, 28, 500-519. [CrossRef]

9. Iannaccone, G.; Marcucci, E.; Gatta, V. What Young E-Consumers Want? Forecasting Parcel Lockers Choice in Rome. Logistics 2021, 5, 57. [CrossRef]

10. Morganti, E.; Seidel, S.; Blanquart, C.; Dablanc, L.; Lenz, B. The Impact of E-commerce on Final Deliveries: Alternative Parcel Delivery Services in France and Germany. Transp. Res. Procedia 2014, 4, 178-190. [CrossRef]

11. Norman, H. Deutsche Post DHL Plans Expansion of DHL Packstation Network. Available online: https://www. parcelandpostaltechnologyinternational.com/news/last-mile/deutsche-post-dhl-plans-expansion-of-dhl-packstationnetwork.html (accessed on 19 March 2021).

12. Lother, S. Deutsche Post: Kritik Nach Weitreichender Ankündigung-Als Die Post Reagiert, Machen Nutzer Klare Ansagen. Available online: https:/ / www.fr.de/panorama/deutsche-post-dhl-packstation-paket-filialen-ausbau-ankuendigung-frankfurtkritik-1tt-zr-90246378.html (accessed on 19 March 2021).

13. Choo, C. Impact of a Delivery Point Network for Urban E-Commerce Deliveries; Singapore University of Technology and Design: Singapore, 2016.

14. Boysen, N.; Fedtke, S.; Schwerdfeger, S. Last-mile delivery concepts: A survey from an operational research perspective. OR Spectrum 2021, 43, 1-58. [CrossRef]

15. Comi, A. A modelling framework to forecast urban goods flows. Res. Transp. Econ. 2020, 80, 1-11. [CrossRef]

16. Lindholm, M. Urban freight transport from a local authority perspective-A literature review. Eur. Transp. 2013, $54,1-37$.

17. Lindholm, M. A sustainable perspective on urban freight transport: Factors affecting local authorities in the planning procedures. Procedia-Soc. Behav. Sci. 2010, 2, 6205-6216. [CrossRef]

18. Russo, F.; Comi, A. Urban Freight Transport Planning towards Green Goals: Synthetic Environmental Evidence from Tested Results. Sustainability 2016, 8, 381. [CrossRef]

19. Boyer, K.K.; Frohlich, M.T.; Hult, G.T.M. Extending the Supply Chain: How Cutting-Edge Companies Bridge the Critical Last Mile into Customers' Homes, 1st ed.; American Management Association: New York, NY, USA, 2004; ISBN 978-0814408360.

20. Gevaers, R.; van de Voorde, E.; Vanelslander, T. Characteristics and Typology of Last-mile Logistics from an Innovation Perspective in an Urban Context. In City Distribution and Urban Freight Transport: Multiple Perspectives; Macharis, C., Melo, S., Eds.; Elgar: Cheltenham, UK, 2011; pp. 56-71. ISBN 978-0857932747.

21. Joerss, M.; Schröder, J.; Neuhaus, F.; Klink, C.; Mann, F. Parcel delivery: The Future of Last Mile. Available online: https: / / mck.co/389DOdZ (accessed on 19 March 2021).

22. Asdecker, B. How Dare You Replace My Deliveryman?! Acceptance of Last-Mile Transportation Innovations-A Qualitative Perspective. AMCIS 2020 Proc. 2020, 24, 1-10.

23. Mangiaracina, R.; Perego, A.; Seghezzi, A.; Tumino, A. Innovative solutions to increase last-mile delivery efficiency in B2C e-commerce: A literature review. IJPDLM 2019, 49, 901-920. [CrossRef]

24. Popper, B. Amazon Key Is a New Service That Lets Couriers Unlock Your Front Door. Available online: https:/ / www.theverge. com/2017/10/25/16538834/ (accessed on 19 March 2021).

25. Hübner, A.H.; Kuhn, H.; Wollenburg, J. Last mile fulfilment and distribution in omni-channel grocery retailing: A strategic planning framework. Int. J. Retail. Distrib. Manag. 2016, 44, 228-247. [CrossRef]

26. Deutsch, Y.; Golany, B. A parcel locker network as a solution to the logistics last mile problem. Int. J. Prod. Res. 2018, 56, 251-261. [CrossRef]

27. IPC. Secure Electronic Parcel Lockers: Postal Industry Overview. Available online: https://www.ipc.be/ \{\}/media/Documents/ PUBLIC/Markets/e-lockers.pdf (accessed on 19 March 2021).

28. Iwan, S.; Kijewska, K.; Lemke, J. Analysis of Parcel Lockers' Efficiency as the Last Mile Delivery Solution-The Results of the Research in Poland. Transp. Res. Procedia 2016, 12, 644-655. [CrossRef]

29. Kämäräinen, V.; Saranen, J.; Holmström, J. The reception box impact on home delivery efficiency in the e-grocery business. IJPDLM 2001, 31, 414-426. [CrossRef]

30. McKinnon, A.C.; Tallam, D. Unattended delivery to the home: An assessment of the security implications. Int. J. Retail. Distrib. Manag. 2003, 31, 30-41. [CrossRef]

31. DHL. DHL Now Delivering to Trunks of VW Cars. Available online: https://www.logistics.dhl/global-en/home/press/pressarchive/2017/ dhl-now-delivering-to-trunks-of-vw-cars.html (accessed on 19 March 2021).

32. Hepp, S.B. Innovation in Last Mile Delivery: Meeting evolving customer demands-The case of In-Car Delivery. Master Thesis, Universidade Catolica Portuguesa, Lisbon, Portugal, 2018.

33. Wang, X.; Yuen, K.F.; Wong, Y.D.; Teo, C.C. An innovation diffusion perspective of e-consumers' initial adoption of self-collection service via automated parcel station. Int. J. Logist. Manag. 2018, 29, 237-260. [CrossRef]

34. Gatta, V.; Marcucci, E.; Nigro, M.; Serafini, S. Sustainable urban freight transport adopting public transport-based crowdshipping for B2C deliveries. Eur. Transp. Res. Rev. 2019, 11, 13. [CrossRef]

35. Punel, A.; Ermagun, A.; Stathopoulos, A. Studying determinants of crowd-shipping use. Travel Behav. Soc. 2018, 12, 30-40. [CrossRef] 
36. Punel, A.; Stathopoulos, A. Modeling the acceptability of crowdsourced goods deliveries: Role of context and experience effects. Transp. Res. Part E Logist. Transp. Rev. 2017, 105, 18-38. [CrossRef]

37. Yuen, K.F.; Wang, X.; Ma, F.; Wong, Y.D. The determinants of customers' intention to use smart lockers for last-mile deliveries. J. Retail. Consum. Serv. 2019, 49, 316-326. [CrossRef]

38. Wang, X.; Yuen, K.F.; Wong, Y.D.; Teo, C.-C. E-consumer adoption of innovative last-mile logistics services: A comparison of behavioural models. Total Qual. Manag. Bus. Excell. 2020, 31, 1381-1407. [CrossRef]

39. Vakulenko, Y.; Hellström, D.; Hjort, K. What's in the parcel locker? Exploring customer value in e-commerce last mile delivery. J. Bus. Res. 2018, 88, 421-427. [CrossRef]

40. Buldeo Rai, H.; Verlinde, S.; Macharis, C. Unlocking the failed delivery problem? Opportunities and challenges for smart locks from a consumer perspective. Res. Transp. Econ. 2019, 87, 100753. [CrossRef]

41. Musolino, G.; Rindone, C.; Vitetta, A. Passengers and freight mobility with electric vehicles: A methodology to plan green transport and logistic services near port areas. Transp. Res. Procedia 2019, 37, 393-400. [CrossRef]

42. Fishbein, M.; Ajzen, I. Predicting and Changing Behavior: The Reasoned Action Approach; Psychology Press: New York, NY, USA; Hove, UK, 2010; ISBN 978-1138995215.

43. Patton, M.Q. Qualitative Research E Evaluation Methods: Integrating Theory and Practice, 4th ed.; SAGE: Los Angeles, CA, USA; London, UK; New Delhi, India; Singapore; Washington, DC, USA, 2015; ISBN 978-1412972123.

44. Eisenhardt, K.M. Building Theories from Case Study Research. Acad. Manag. Rev. 1989, 14, 532-550. [CrossRef]

45. Howland, D. How Retail's Gender Gap Affects Retailers. Available online: https://www.retaildive.com/news/how-retailsgender-gap-affects-retailers/376720/ (accessed on 19 March 2021).

46. Jezerc, G. Mind the Gap: The Gender Effect on Shopping Habits and Technology Disruptors; First Insight, Inc.: Warrendale, PA, USA, 2018.

47. Mayring, P. Qualitative Content Analysis. Forum Qual. Soc. Res. 2000, 1, 1-10. [CrossRef]

48. Ajzen, I. The theory of planned behavior. Organ. Behav. Hum. Decis. Process. 1991, 50, 179-211. [CrossRef]

49. Silverman, D. Doing Qualitative Research: A Practical Handbook, 4th ed.; reprinted; SAGE Publications: Los Angeles, CA, USA, 2013; ISBN 9781446289204.

50. Krippendorff, K. Content Analysis: An Introduction to Its Methodology, 2rd ed.; SAGE Publications: Thousand Oaks, CA, USA, 2009; ISBN 9780761915454.

51. Lincoln, Y.S.; Guba, E.G. Naturalistic Inquiry; [Nachdr.]; SAGE: Newbury Park, CA, USA, 2007; ISBN 9780803924314.

52. Endler, N.S. The Effects of Verbal Reinforcement on Conformity and Deviant Behavior. J. Soc. Psychol. 1965, 66, 147-154. [CrossRef]

53. Pavlou, P.A.; Fygenson, M. Understanding and Predicting Electronic Commerce Adoption: An Extension of the Theory of Planned Behavior. MIS Q. 2006, 30, 115-143. [CrossRef]

54. Cheng, E.W.L. Choosing between the theory of planned behavior (TPB) and the technology acceptance model (TAM). Educ. Technol. Res. Dev. 2019, 67, 21-37. [CrossRef]

55. Lanzolla, G.; Suarez, F.F. Closing the Technology Adoption-Use Divide. J. Manag. 2012, 38, 836-859. [CrossRef]

56. Whetten, D.A. What Constitutes a Theoretical Contribution? Acad. Manag. Rev. 1989, 14, 490-495. [CrossRef]

57. Venkatesh, V.; Morris, M.G.; Davis, G.B.; Davis, F.D. User Acceptance of Information Technology: Toward a Unified View. MIS Q. 2003, 27, 425-478. [CrossRef] 